\title{
Comparison of the Effect and Durability of Lumbar Stabilization and Global Postural Reeducation Exercises on Movement Control, Pain and Disability in Men with Lumbar Movement Control Dysfunction
}

\author{
Abolfazl Rahmani ${ }^{1}$, Hooman Minoonejad ${ }^{2 *}{ }^{*}$, Foad Seidi $^{2 *}$, Yousef Moghdas Tabrizi ${ }^{2}$ \\ ${ }^{1}$ Faculty of Physical Education and Sport Sciences, University of Tehran, Tehran, Iran \\ ${ }^{2}$ Department of Health and Sport Medicine, Faculty of Physical Education and Sport Sciences, University of Tehran, Tehran, \\ Iran
}

\section{*Correspondence to}

Hooman Minoonejad

Email: hoomanminoonejad@ut.ac.ir,

Foad Seidi,

Email: foadseidi@ut.ac.ir

Received August 23, 2020

Accepted October 12, 2020

Published online March 31, 2021

Please cite this article as follows: Rahmani $A$ Minoonejad $\mathrm{H}$, Seidi F, Moghdas Tabrizi

Y. Comparison of the effect and durability of lumbar stabilization and global postural reeducation exercises on movement control, pain and disability in men with lumbar movement control dysfunction. Int J Basic Sci Med. 2021;6(1):17 24. doi:10.34172/ ijbms.2020.03.

\begin{abstract}
Introduction: The global postural reeducation (GPR) method seems to be an effective method for the treatment of musculoskeletal disorders; therefore, the aim of this study was to compare the effect and durability of 6 weeks of GPR and lumbar stability exercises on movement control, pain and disability in men with chronic nonspecific low back pain (NSLBP) with lumbar movement control dysfunction.

Methods: Based on the inclusion and exclusion criteria, 46 men with non-specific chronic low back pain (LBP) with lumbar movement control dysfunction were selected and randomly divided into three groups (two exercise groups - one control group). Training intervention groups practiced for six weeks, three sessions per week. Visual analogue scale (VAS), Roland Morris questionnaire, and movement control test were used to measure pain, level of physical disability, and lumbar movement control, respectively. Repeated measures ANOVA was utilized to compare the effect and durability of the two training protocols on the dependent variables at a significant level.

Results: Results from this research showed that both types of exercises reduced pain $(P=0.001)$ and improved disability index $(P=0.001)$ and lumbar movement control $(P=0.001)$. Our findings suggested that a GPR intervention for 6 weeks $(P=0.040)$ and inactivity for 4 weeks $(P=0.001)$ resulted in a greater improvement in disability compared to the lumbar stabilization exercises (LSEs).

Conclusion: Both types of exercises seem to be effective in improving lumbar movement control, pain, and disability in people with movement control dysfunction after both training and inactivity. The GPR method improved disability more than the LSEs.

Keywords: Low back pain, Global postural reeducation, Stabilization exercises, Disability, Motor control impairment
\end{abstract}

\section{Introduction}

Low back pain (LBP) is one of the main health problems in many countries with economic and social effects. ${ }^{1,2}$ First symptoms often occur between the age of 30 and $50 .^{2}$ LBP is characterized as pain, muscle tension, or stiffness below the costal margin and above the inferior gluteal folds, with or without leg pain. ${ }^{3}$ Due to the unknown causes of many LBPs, they are referred to as nonspecific low back pain (NSLBP), which in NSLBP impairs the function of the deep muscles that protect the spine. ${ }^{4}$ Approximately $80 \%$ of its variants include NSLBP, about $10 \%$ of which is chronic. ${ }^{5}$ Chronic NSLBP is defined as LBP with no pathological evidence and with a history of more than 3 months. ${ }^{6}$ The studies show that movement control impairment (MCI) is one of the mechanisms of NSLBP that can be caused by pain, abnormal tissue loading, lack of proprioceptive awareness, or absence of a withdrawal reflex motor response.

(C) 2021 The Author(s); Published by Zabol University of Medical Sciences. This is an open-access article distributed under the terms of the Creative Commons Attribution License (http://creativecommons.org/licenses/by/4.0), which permits unrestricted use, distribution, and reproduction in any medium, provided the original work is properly cited. 
It seems that the proprioceptive impairment causes painful sensory stimuli produced by mechanical damage to the lumbar region. Physiologically, pain messages increase the sensitivity of mechanical receptors in people with LBP, and as a result, accurate messages are not sent to the central nervous system. ${ }^{8}$ According to various theories and studies, LPB is associated with abnormal movement strategies due to changes in neuromuscular control, causing abnormal recruiting of fibers and levels of muscle activity, resulting in impaired muscle balance. ${ }^{9}$

Some studies have shown the important role of exercise in reducing $\mathrm{LBP}^{10}$. Today, most exercise methods are considered more than non-surgical treatments which directly strengthen the muscles around the lower back. ${ }^{11}$ Lumbar stabilization exercise (LSE) is one of the most common strategies for the treatment of LBP, which emphasizes the training of deep stabilization of lumbar muscle contraction. ${ }^{12}$ In recent research on the treatment of NSLBP, researchers have focused on exercises that, in addition to stabilizing the back by focusing on deep trunk muscles, improve lumbar motor control by enhancing endurance and strength of abdominal muscles and extensors. ${ }^{12}$

Global postural reeducation (GPR) is one of the therapeutic methods that has recently attracted much attention. GPR was created by the physiotherapist Philippe Souchard in 1980 to treat postural disorders as a result of changes in the biomechanical system arising from morphological, behavioral, and psychological factors. ${ }^{13}$ This method of treatment is based on strong biomechanical and physiological concepts, and it considers three primary principles when dealing with neuromusculoskeletal disorders. The first one is individualism, the idea that people are essentially different from one another. The second is causality, which aims to obtain a permanent and real solution to a problem, and finally, the third one is the assumption that the whole body must be evaluated and treated. ${ }^{14}$ The aim of GPR is to stretch the shortened muscles by the creep characteristic of viscoelastic tissue, and by enhancing the contraction of the antagonist muscles to avoid postural asymmetry. This method is based on determining posterior and anterior muscular chains as well as the stretching of antigravity muscles. ${ }^{15}$

Although the GPR method is used in many countries, only a few studies support their clinical and theoretical effects. Previous studies have shown that this method is effective in the treatment of some musculoskeletal diseases including NSLBP, disc herniation, and ankylosing spondylitis. ${ }^{15}$ Bonetti and et al compared the effectiveness of a GPR with stability exercises in LBP. The results showed that GPR and SE in LBP, both in the short-term and mid-term, led to an improvement in pain and disability. ${ }^{15}$ The results of a study by Castagnoli et al on the effects of short- and long-term GPR on chronic LPB indicated that statistically and clinically there was an improvement in pain and performance of training groups compared to the control group. After one year, however, it was reported that the pain only improved significantly in the group that did GPR exercises. ${ }^{16}$ Paolucci et al reviewed LBP and postural rehabilitation exercises, confirming the durability of the long-term effects of GPR exercises. However, they found it difficult to consider this method superior to other methods because this needed further high-quality research that can prove the effects of this technique with appropriate measurement methods. ${ }^{17}$

Therefore, based on the introduction, the study aimed to compare the effect and durability of six weeks of LSE and GPR exercises on pain and disability in men with NSLBP suffering from MCI.

\section{Materials and Methods}

This research was quasi-experimental due the existence of an intervention and a control group, the purposeful selection of subjects, and the impossibility of controlling all interfering variables in the research. Participants were men aged 30 to 40 years with chronic non-specific LBP and lumbar movement control dysfunction, without anatomical and pathological lesions based on detailed examinations and suffered pain which lasted for more than 12 weeks. The number of samples in this study was estimated after a pilot study using $G^{\star}$ Power software with a test power of $80 \%$ and a reliability coefficient of $95 \%$, the number of participants was 39 in 3 groups. ${ }^{18}$ Due to the probability of losing samples, 46 men with chronic NSLBP with movement control disorders were divided into three groups of GPR $(n=17)$, LSE $(n=17)$, and control $(n=12)$ that were homogeneous in terms of pain, height, and weight to control for the effects of such interfering variables as much as possible. The purpose of the research and the implementation method were first explained. The written consent and personal information were obtained. The participants showed no pathological symptoms, history of fractures, tumors, surgery, or joint diseases of the spine, pelvis, and lower limbs. Inclusion criteria included having two defects in performing the diagnostic test of movement control disorder, ${ }^{19,20}$ RolandMorris questionnaire score above $4,{ }^{21}$ pain range (6-3) on the visual analogue scale (VAS), not having functional or congenital kyphosis and Lordosis (higher than 42 and 52 degrees measured by the flexible ruler), ${ }^{22,}{ }^{23}$ not having scoliosis (rotation above 5 degrees by scoliometer), ${ }^{24}$ and no clear observation of any abnormalities in the structure of the lower limb in different views. Exclusion criteria included unwillingness to continue cooperation, severe pain during the tests to make participation impossible, back pain of non-mechanical origin, absence in two consecutive or three non-consecutive sessions, not participating in the second and third tests up to one week after the planned schedule, use of painkillers and muscle relaxants, and drug and alcohol addiction. 


\section{Procedure}

Before starting, the measuring stations were determined and the measuring instruments and environment in terms of light and temperature were prepared. The statistical population consisted of men aged 30 to 40 with chronic NSLBP and lumbar movement control dysfunction. To determine the level of physical disability, the participants answered the questions of the Roland Morris Disability Questionnaire. The reliability of this questionnaire was about $91 \% .{ }^{25}$ If the participants had a questionnaire score above 4, they were then tested for lumbar movement control by Luomajoki et $\mathrm{al}^{20}$ and had to have at least two defects in the tests to be included in the study. Then, lower extremity abnormalities were observed and the position of the thoracic and lumbar arches of the spine was measured using a flexible ruler and the amount of rotation of the vertebrae was measured by a tester with a scoliometer. If there were visible abnormalities in the lower extremities and the angle of kyphosis and increased lordosis and the rotation of the vertebrae was more than 5 degrees, or if only the participants had a problem with lumbar dysfunction they would be removed from the study. VAS was used to measure pain. The internal reliability of this scale has been reported to be between $77 \%$ and $79 \% .{ }^{26}$ After identifying and placing the participants in the groups, a written program of lumbar stability exercises and GPR exercises was implemented for 6 weeks, 3 sessions each week, in the intervention groups. By the end of the exercise and also after 4 weeks of inactivity, the amount of pain and the score of the Roland-Morris questionnaire and the movement control tests in all three groups were measured. It is worth mentioning that performing tests and implementing training interventions lasted approximately 12 weeks in Mehr Health and Corrective Exercises Center in Qazvin.

\section{Movement Control Tests}

These tests were performed by the following method. Firstly, the movement was shown to all of the participants. Then, if a participant performed incorrectly, the correct method of performance was explained to him. After learning the correct movement, if he was still not able to perform the movement correctly, it was concluded that he suffered a movement control dysfunction. The criterion for being included in the present research was to suffer at least two dysfunctions in performing the tests. ${ }^{20}$ The subject was asked to wear sports shorts so that his entire spine, pelvis, and lower limbs were visible. Each performance was repeated three times and recorded by taking photos. According to the opinion of an expert in diagnosis of movement control dysfunction, a score was assigned to each performance of each participant so that scores 1,2, and 3 indicated the lack of any movement control dysfunction, a minor movement control dysfunction, and severe movement control dysfunction, respectively. The average of the scores represented the total score of the test. All six movement control tests were performed in this way. ${ }^{27}$

\section{Lumbar Stabilization Exercises}

In the present study, LSEs were used to create segmental stability and improve movement control with qualifying and quantifying movements. Exercises were done under the direct supervision of the examiner. The approximate time of each exercising session was between 40 and 50 minutes. These exercises were in 6 weeks of 3 sessions. There was a 48-hour interval between exercise sessions. The exercises were designed to be progressive in which the responsibility for the decision to progress in the exercise was based on pain intensity, observation of the quality of the exercise, movement control in the performance (lumbar stability), fatigue, and adaptation to overload during the exercises by the examiner. The exercises were performed according to Table $1 .^{12}$

\section{Global Postural Reeducation}

In this research, to perform the GPR method, postures primarily involving the posterior chain length were selected as this chain is shortened in patients with NSLBP. This method included 8 treatment postures of lying, sitting, and standing. Five items of supine lying with abducted hands and open thighs angel, supine lying with abducted hands and closed of thighs angle, sitting with adducted hands and closed thighs angle, standing and bending the trunk forward, and standing against the wall and opening the angle of thighs were performed as shown in Table 2. The duration of each item varied from 5 to 15 minutes. These exercises were done for 6 weeks, three sessions each week. ${ }^{14,15}$

Table 1. Lumbar Stabilization Exercises

\begin{tabular}{ll}
\hline Phases & Exercises Program \\
\hline Phase I: Lumbar stabilization & $\begin{array}{l}\text { 1. Normal breathing (never hold your breath), 2. This part involves a movement or support of a } \\
\text { position and must be done while exhaling. }\end{array}$ \\
Phase II: Motor control exercises & $\begin{array}{l}\text { 1. Pelvic tilt, 2. Abdominal drawing-in manoeuver, } \\
\text { 3. Strengthen multifidus }\end{array}$ \\
& $\begin{array}{l}\text { 1. Curl-ups, 2. Dead bug, 3. Bird dog, } \\
\text { Phase III: Overload exercises }\end{array}$ \\
& 7. Seated hip flexion, 5 . Heel slides, 6. Bridge, \\
\end{tabular}




\section{Statistical Methods}

Descriptive and inferential statistics were used to analyze the data. First, data related to the demographic characteristics of the participants were presented and the results obtained from evaluating the variables in all three stages of the test were reported in the form of the means and standard deviations in tables. Regarding inferential statistics, after collecting data and confirming the normal distribution of data using the Shapiro-Wilk test, the repeated measures analysis of variance (ANOVA) at a significance level of 0.05 was used to compare the means at baseline, at 6 weeks and at 4 weeks, the analysis of covariance (ANCOVA) was used to compare intergroup differences, and the Bonferroni post hoc test was used for pairwise comparisons. The results were analyzed by SPSS software version 22 and descriptive and inferential statistics.

\section{Results}

Table 3 shows the mean and standard deviation of the demographic characteristics of the participants. The results of the analysis of variance indicated that there was no significant difference between age, height, weight, and body mass index of the three groups $(P>0.05)$ and that the groups were homogeneous in these variables.

Table 4 presents the descriptive results obtained from evaluating the variables in all three stages of the test in the form of the means and standard deviations as well as the results obtained from repeated measures ANOVA for the indices of movement control, pain, and disability. The results showed that in the LSE and GPR groups, the movement control, pain, and disability at 6 weeks and at 4 weeks were significantly different from baseline $(P \geq 0.05)$. No significant difference was observed in all indicators of the control group at 6 weeks and at 4 weeks with baseline $(P>0.05)$.

The findings in Table 5 compare the effect of LSE and GPR on lumbar movement control, pain, and disability using the ANCOVA test with baseline as a curette. After determining the significant difference between the three groups, the Bonferroni post hoc test was run to investigate the two-by-two changes in different stages of measurement. The results showed that there was no significant difference $(P>0.05)$ between the mean scores of the lumbar movement control and pain at 6 weeks $(P=1.000, P=1.000)$ and at 4 weeks $(P=0.772, P=1.000)$ for both the GPR group and LSE group, respectively. There was a significant difference $(P \geq 0.05)$ between the mean scores of the lumbar movement control and pain at 6 weeks $(P=0.001, P=0.001)$ and at 4 weeks $(P=0.001$, $P=0.001)$ for both the control group and two training groups, respectively.

The results of the Bonferroni post hoc test showed that there was a significant difference between the mean scores of GPR group disability and LSE group at 6 weeks $(P=0.040)$ and at 4 weeks $(P=0.001, P \geq 0.05)$. This difference is in favor of GPR exercises. Also, there is a significant difference between the mean scores of the disability index in the control group with the two training groups at 6 weeks $(P=0.001)$ and at 4 weeks $(P=0.001, P \geq$ $0.05)$. High values of Eta Squared indicate the significant effect of exercise on the lumbar movement control, pain, and disability indicators.

\section{Discussion}

The study compared the effect and durability of two conventional and new methods of LSE and GPR exercises

Table 3. Individual Characteristics of the Subjects in the Experimental and Control Groups

\begin{tabular}{lcccc}
\hline Variable & Control & LSE & GPR & P Value \\
\hline Age $(\mathrm{y})$ & $34.3 \pm 3.11$ & $34.1 \pm 2.87$ & $33.3 \pm 2.45$ & 0.59 \\
High $(\mathrm{cm})$ & $173.5 \pm 6.51$ & $171 \pm 3.71$ & $172.5 \pm 4.78$ & 0.41 \\
Wright $(\mathrm{kg})$ & $74.9 \pm 6.98$ & $70.4 \pm 5.22$ & $71.4 \pm 5.23$ & 0.11 \\
BMl & $24.83 \pm 0.88$ & $24.02 \pm 1.46$ & $23.95 \pm 1.30$ & 0.16 \\
\hline
\end{tabular}

Abbreviations: BMI, body mass index; LSE, lumbar stabilization exercises; GPR, global postural reeducation.

Table 2: The Global Postural Reeducation Exercises

\begin{tabular}{ll}
\hline Posture & Performance \\
\hline $\begin{array}{l}\text { The lying posture with the extension of the } \\
\text { legs aimed to release the diaphragm muscle } \\
\text { and to stretch the anterior muscle chain }\end{array}$ & $\begin{array}{l}\text { Participants maintained this breathing across the entire session. The supine position (also called "frog on the } \\
\text { ground") emphasizes the stretching of the anterior muscle chain and starts with participants lying on their } \\
\text { backs with upper limbs abducted at approximately } 30^{\circ} \text { and supine forearms. Hips were flexed, abducted, and } \\
\text { laterally rotated, with foot soles touching each other. }\end{array}$ \\
$\begin{array}{l}\text { The lying posture with flexion of the legs was } \\
\text { intended to stretch the posterior chain }\end{array}$ & $\begin{array}{l}\text { The initial position involved lying with the hip flexed and progression involved increasing hip flexion, knee } \\
\text { extension, and dorsiflexion of the ankle. }\end{array}$ \\
$\begin{array}{l}\text { The sitting posture, the hands are close to the } \\
\text { body and the hip is at a closed angle }\end{array}$ & $\begin{array}{l}\text { The participant was sitting on a chair, the hands were close to the body and the hip was at a closed angle and } \\
\text { the legs were open and close to the body, the thighs were bent and the trunk was bent forward. This posture } \\
\text { was used to stretch the posterior chain. }\end{array}$ \\
$\begin{array}{l}\text { The bending-forward posture with flexion of } \\
\text { the trunk }\end{array}$ & $\begin{array}{l}\text { The standing posture accompanied by flexion of the trunk took place from an upright posture to a bending } \\
\text { forward position, while keeping the occiput, the thoracic spine, and the sacrum aligned. This posture was used } \\
\text { to stretch the posterior chain. }\end{array}$ \\
$\begin{array}{l}\text { The standing posture against the wall where the angle of the thigh was open. Legs were in a semi-bent position, } \\
\text { posterior pelvic tilt, external rotation thigh, and legs on the floor. This posture was used to stretch the anterior } \\
\text { chain. }\end{array}$
\end{tabular}


Table 4. The Within-Subject Analysis for Comparing the Effect of Exercises in the Three Groups

\begin{tabular}{|c|c|c|c|c|c|}
\hline Variable & Group & $\begin{array}{c}\text { Baseline } \\
\text { Mean } \pm \text { SD }\end{array}$ & $\begin{array}{c}6 \text { Weeks } \\
\text { Mean } \pm \text { SD }\end{array}$ & $\begin{array}{c}4 \text { Weeks } \\
\text { Mean } \pm \text { SD }\end{array}$ & $P$ Value \\
\hline \multirow{3}{*}{ Pain } & Control & $4.58 \pm 0.99$ & $4.50 \pm 1.17$ & $4.25 \pm 0.87$ & 0.384 \\
\hline & LSE & $4.35 \pm 1.06$ & $1.29 \pm 1.05$ & $1.41 \pm 1.21$ & $0.001 *$ \\
\hline & GPR & $4.35 \pm 0.93$ & $1.18 \pm 1.13$ & $1.47 \pm 1.54$ & $0.001 *$ \\
\hline \multirow{3}{*}{ Disability } & Control & $10.83 \pm 3.21$ & $10.42 \pm 2.68$ & $10.17 \pm 2.62$ & 0.116 \\
\hline & LSE & $10.23 \pm 2.79$ & $4.06 \pm 2.56$ & $4.47 \pm 2.58$ & $0.001 *$ \\
\hline & GPR & $10.70 \pm 2.87$ & $3.41 \pm 2.03$ & $3.59 \pm 1.80$ & $0.001 *$ \\
\hline \multirow{3}{*}{$\begin{array}{l}\text { Lumbar movement } \\
\text { control }\end{array}$} & Control & $10.61 \pm 1.30$ & $10.81 \pm 1.61$ & $10.69 \pm 1.47$ & 0.370 \\
\hline & LSE & $10.52 \pm 1.16$ & $7.02 \pm 0.63$ & $7.56 \pm 0.57$ & $0.001 *$ \\
\hline & GPR & $10.07 \pm 1.34$ & $6.78 \pm 0.59$ & $7.07 \pm 0.67$ & ${ }^{*} 0.001$ \\
\hline
\end{tabular}

Abbreviations: LSE, lumbar stabilization exercises; GPR, global postural reeducation.

* $P \geq 0.05$.

Table 5. The Between-Subject Analysis for Comparing the Effect of Exercises in the Three Groups

\begin{tabular}{|c|c|c|c|c|c|c|}
\hline & Group & Per Steps & Mean $^{a}$ & Mean Difference & $P$ Value & Eta Squared \\
\hline \multirow{3}{*}{ Pain } & Control & 6 weeks & 4.39 & - & \multirow{3}{*}{$0.001 *$} & \multirow{3}{*}{0.702} \\
\hline & LSE & 6 weeks & 1.33 & -3.06 & & \\
\hline & GPR & 6 weeks & 1.21 & -3.18 & & \\
\hline \multirow{3}{*}{ Pain } & Control & 4 weeks & 4.14 & - & \multirow{3}{*}{$0.001^{*}$} & \multirow{3}{*}{0.557} \\
\hline & LSE & 4 weeks & 1.45 & -2.69 & & \\
\hline & GPR & 4 weeks & 1.51 & -2.63 & & \\
\hline \multirow{3}{*}{ Disability } & Control & 6 weeks & 10.22 & - & \multirow{3}{*}{$0.001 *$} & \multirow{3}{*}{0.877} \\
\hline & LSE & 6 weeks & 4.30 & -5.92 & & \\
\hline & GPR & 6 weeks & 3.31 & -6.91 & & \\
\hline \multirow{3}{*}{ Disability } & Control & 4 weeks & 9.97 & - & & \multirow{3}{*}{0.915} \\
\hline & LSE & 4 weeks & 4.72 & -5.25 & $0.001^{*}$ & \\
\hline & GPR & 4 weeks & 3.48 & -6.48 & & \\
\hline \multirow{3}{*}{$\begin{array}{l}\text { Lumbar movement } \\
\text { control }\end{array}$} & Control & 6 weeks & 10.70 & - & \multirow{3}{*}{$0.001 *$} & \multirow{3}{*}{0.858} \\
\hline & LSE & 6 weeks & 6.94 & -3.76 & & \\
\hline & GPR & 6 weeks & 6.95 & -3.75 & & \\
\hline \multirow{3}{*}{$\begin{array}{l}\text { Lumbar movement } \\
\text { control }\end{array}$} & Control & 4 weeks & 10.59 & - & \multirow{3}{*}{$0.001^{*}$} & \multirow{3}{*}{0.796} \\
\hline & LSE & 4 weeks & 7.50 & -3.09 & & \\
\hline & GPR & 4 weeks & 7.20 & -3.39 & & \\
\hline
\end{tabular}

Abbreviations: LSE, lumbar stabilization exercises; GPR, global postural reeducation.

${ }^{a}$ Adjusted based on baseline values/negative values indicate improvements.

$* P \geq 0.05$.

on pain and disability in men with chronic NSLBP and lumbar movement control dysfunction. The results suggested that both exercise methods reduced pain and improved disability and lumber movement control. Additionally, the results of our study showed that after a 6-week exercise, the GPR exercises were significantly more effective in improving the disability of people with chronic NSLBP and lumber movement control dysfunctions at 6 weeks and at 4 weeks of non-training than LSE exercises. The basis of the GPR method is that the muscles organize themselves in coordinated chains of motion and do not work as separate structures. Thus, a change (shortening or stretching) of one or more muscles in the chain produces a compensatory response in adjacent or distant muscles. ${ }^{15,16}$ According to the parameters of this method, to heal the muscle, the entire chain to which the muscle belongs must be stretched together continuously to prevent possible compensation. For this purpose, the GPR method focuses on postural reeducation. ${ }^{14}$ As the results showed, patients with LBP suffer from decreased spinal stability, insufficiency of proprioception sense, impaired neuromuscular coordination, impaired posture control, and weakness in range of motion, factors which eventually lead to pain..$^{28}$ Moreover, the results of the study by Comer et al. (as cited in Ershad and Kahrizi) indicated that there was a higher rate of error in the repositioning 
of the forward bending in patients with chronic LBP than healthy people. ${ }^{29}$ Movement control dysfunction caused by tissue injuries such as ligament injury leads to pain. ${ }^{30}$ After the initial injury and pain, changes are made in the movements of lumbar spine to reduce pain. This protective mechanism is useful for short-term pain relief, but reduces the range of motion and increases the pressure of load on muscles and joints in the long run. ${ }^{31}$ The inappropriate posture of people with chronic LBP may be due to pain, causing asymmetric pressure on different joints, especially in the lumbar region. Some studies have shown that in patients with chronic LBP, without observing any restriction in their lumbar movements, there are abnormalities in their movements that may indicate a lack of control of their lumbar movements, which is another reason for asymmetric pressure on the lumbar spine which can cause and exacerbate LBP. Exercise therapy prevents incorrect physical mechanics (leading to fatigue) by enhancing strength, endurance, and muscle balance, and reduces back pain and injury. ${ }^{32}$ Thus, we offered GPR exercises to these individuals (active integrated stretching postures with isometric contractions), which inhibits the activity of agonist muscles and stimulates antagonist muscles, causing the spindle to stretch. ${ }^{33}$ In individuals with chronic LBP, this can lead to improved spinal mobility, reduced pain, and subsequently improved posture. ${ }^{33} \mathrm{Da}$ Silva et al showed the effect of GPR exercises on pain in patients with chronic NSLBP. ${ }^{34}$ Adopting an inappropriate posture after an LBP crisis will upset the balance of forces in the postural chains. GPR through static muscle stretching aims to reduce muscle tension and additional load on specific structures and to restore range of motion in that segment, thereby reducing pain in the area. ${ }^{34}$ The results of a study by Sheikhi indicated that GPR exercises significantly reduced pain in patients with chronic NSLBP with movement control dysfunction. ${ }^{35}$

In line with the results of other studies, the present study has shown that performing stability exercises leads to a reduction in pain and disability in people with chronic $\mathrm{LBP}^{36}$ and reduces the recurrence of $\mathrm{LBP}{ }^{37}$ It seems that the basis of LSE is to adapt to the proprioception sense that receives stimuli in high-risk situations. This information can modify planned responses to risk factors for LBP. Then, corrective responses begin to adjust to reduce the stress on the back. Thus, these exercises have a significant impact on the onset of trunk muscle activity before trunk movement and improve deep muscle coordination to control movements in individuals with chronic NSLBP to reduce pain and improve disability.

However, in various studies, the effect of non-exercising on physiological parameters in the short-term (less than 4 weeks) and long-term (more than 4 weeks) periods has been evaluated. ${ }^{38}$ One of the prominent features of skeletal muscle is plasticity that changes when there is no exercise. ${ }^{39}$ The results show that GPR can be an effective approach to the treatment of musculoskeletal pain, affecting movement control, pain, and disability after the exercising period. These results were statistically significant and were maintained 4 weeks after the end of the treatment as determined by a follow-up evaluation, showing that GPR exercises had a higher effect at 6 weeks and at 4 weeks of non-training in improving disability than LSE. The results are consistent with the results of the study by Bonetti et al in which GPR and stability exercises were similar in people with LBP, both in the short and medium-term, leading to an improvement in the functional disability. ${ }^{15}$ One of the possible reasons for this superiority could be that neuromuscular retraining, performed with the aim of reducing stiffness and increasing activity in stunted muscles by improving timely relaxation of stunted muscles, improves the performance of the selected muscles. ${ }^{40}$ Similarly, the results of other studies have confirmed the durability of the effects of GPR exercises. ${ }^{17}$ It also seems that poor understanding of muscle physiology, especially the knowledge that static and dynamic muscles have different physiologies and therefore must be treated differently is a common error in conventional physiotherapy. Additionally, the effectiveness of the GPR method lies in the understanding that each person has a unique way of responding to an injury or potential injury in combination with a clear understanding of the biomechanical processes that the body goes through before an injury or pain. By providing insight into muscle physiology, these exercises allow the therapist to provide an effective treatment for each structure, and each person. ${ }^{14,15}$ Therefore, to relieve pain in people with LBP, exercises should be designed to improve all lumber dysfunctions. Considering that in the subgroup of lumbar movement control dysfunction in people with LBP, significant improvement in the movement control and disability was seen in the GPR exercises group, this method may reduce pain in people who suffer from NSLBP with lumbar movement control dysfunction by creating a positive effect on the indicators under investigation. Mainly due to the lack of general knowledge and little evidence on the effectiveness of the GPR method in this subgroup, it is recommended that the effectiveness of this method be examined in future research in different age groups and both genders.

\section{Conclusion}

The results showed that the lumbar movement control, pain and disability of patients with chronic NSLBP with MCI in the LSE and GPR group had a significant improvement at 6 weeks and at 4 weeks of inactivity compared to the baseline. The comparison of the two groups showed that both types of exercise therapy were effective in improving lumber movement control and reducing pain and there was no significant difference in these variables between the two groups. Also, no significant difference was observed in all three stages of the test in terms of pain and disability in the control 
group. The results suggested a positive role for the GPR method in improving the level of disability both in the short-term and med-term. Both groups of exercises are recommended to improve lumbar movement control and relieve pain in people who suffer NSLBP with lumbar movement control dysfunction.

\section{Ethical Approval}

This research was approved by the Ethics Code from the National Ethics Committee in Biomedical Research with number IR.UT. SPORT.REC.1398.053.

\section{Conflict of Interest Disclosure}

The authors have no competing interests.

\section{Authors' Contributions}

The authors contributed equally to this research.

\section{Acknowledgments}

We thank the participants in the study and the anonymous reviewers for their useful comments.

\section{References}

1. Mohseni Bandpei MA, Ehsani F, Behtash H, Ghanipour M. Occupational low back pain in primary and high school teachers: prevalence and associated factors. J Manipulative Physiol Ther. 2014;37(9):702-708. doi:10.1016/j. jmpt.2014.09.006

2. Knezević O, Mirkov D. Trunk muscle activation patterns in subjects with low back pain. Vojnosanit Pregl. 2013;70(3):315-318. doi:10.2298/vsp1303315k

3. Chou R. Low back pain (chronic). BMJ Clin Evid. 2010;2010.

4. Kendall FP, McCreary EK, Provance PG, Rodgers M, Romani WA. Muscles: Testing and Testing and Function with Posture and Pain. US: Lippincott Williams \& Wilkins; 2005:49-118.

5. Elbaz A, Mirovsky Y, Mor A, et al. A novel biomechanical device improves gait pattern in patient with chronic nonspecific low back pain. Spine (Phila Pa 1976). 2009;34(15):E507-512. doi:10.1097/ BRS.0b013e3181a98d3f

6. Bogduk N. Management of chronic low back pain. Med J Aust. 2004;180(2):79-83.

7. Luomajoki HA, Bonet Beltran MB, Careddu S, Bauer CM. Effectiveness of movement control exercise on patients with non-specific low back pain and movement control impairment: a systematic review and meta-analysis. Musculoskelet Sci Pract. 2018;36:1-11. doi:10.1016/j. msksp.2018.03.008

8. Brumagne S, Cordo P, Lysens R, Verschueren S, Swinnen $\mathrm{S}$. The role of paraspinal muscle spindles in lumbosacral position sense in individuals with and without low back pain. Spine (Phila Pa 1976). 2000;25(8):989-994. doi:10.1097/00007632-200004150-00015

9. Henry SM, Hitt JR, Jones SL, Bunn JY. Decreased limits of stability in response to postural perturbations in subjects with low back pain. Clin Biomech (Bristol, Avon). 2006;21(9):881-892. doi:10.1016/j. clinbiomech.2006.04.016
10. Leo Rathinaraj AS, Sreeja MT, Arun B, Sundar KS, Premlal R. A surface electromyographic study to assess the effect of spinal segmental stabilization [multifidus] exercise program in chronic mechanical low back pain patients. Eur Orthop Traumatol. 2012;3(3):161-168. doi:10.1007/ s12570-012-0113-y

11. França FR, Burke TN, Hanada ES, Marques AP. Segmental stabilization and muscular strengthening in chronic low back pain: a comparative study. Clinics (Sao Paulo). 2010;65(10):1013-1017. doi:10.1590/s180759322010001000015

12. Nowotny AH, Calderon MG, de Souza PA, et al. Lumbar stabilisation exercises versus back endurance-resistance exercise training in athletes with chronic low back pain: protocol of a randomised controlled trial. BMJ Open Sport Exerc Med. 2018;4(1):e000452. doi:10.1136/ bmjsem-2018-000452

13. Oliveri M, Caltagirone C, Loriga R, Pompa MN, Versace V, Souchard P. Fast increase of motor cortical inhibition following postural changes in healthy subjects. Neurosci Lett. 2012;530(1):7-11. doi:10.1016/j.neulet.2012.09.031

14. Mercado D. Assessment of the Effects of Global Postural ReEducation on Musicians with Nonspecific Musculoskeletal Pain as Assessed by Questionnaires and Infrared Thermography [dissertation]. University of Ottawa; 2018.

15. Bonetti F, Curti S, Mattioli S, et al. Effectiveness of a 'Global Postural Reeducation' program for persistent low back pain: a non-randomized controlled trial. BMC Musculoskelet Disord. 2010;11:285. doi:10.1186/1471-2474-11-285

16. Castagnoli C, Cecchi F, Del Canto A, et al. Effects in short and long term of Global Postural Reeducation (GPR) on chronic low back pain: a controlled study with one-year follow-up. ScientificWorldJournal. 2015;2015:271436. doi:10.1155/2015/271436

17. Paolucci T, Attanasi C, Cecchini W, Marazzi A, Capobianco SV, Santilli V. Chronic low back pain and postural rehabilitation exercise: a literature review. J Pain Res. 2019;12:95-107. doi:10.2147/jpr.s171729

18. Faul F, Erdfelder E, Lang AG, Buchner A. G*Power 3: a flexible statistical power analysis program for the social, behavioral, and biomedical sciences. Behav Res Methods. 2007;39(2):175-191. doi:10.3758/bf03193146

19. Oesch P, Kool J, Hagen KB, Bachmann S. Effectiveness of exercise on work disability in patients with non-acute non-specific low back pain: systematic review and metaanalysis of randomised controlled trials. J Rehabil Med. 2010;42(3):193-205. doi:10.2340/16501977-0524

20. Luomajoki H, Kool J, de Bruin ED, Airaksinen O. Movement control tests of the low back; evaluation of the difference between patients with low back pain and healthy controls. BMC Musculoskelet Disord. 2008;9:170. doi:10.1186/1471-2474-9-170

21. Wand BM, O'Connell NE, Di Pietro F, Bulsara M. Managing chronic nonspecific low back pain with a sensorimotor retraining approach: exploratory multiple-baseline study of 3 participants. Phys Ther. 2011;91(4):535-546. doi:10.2522/ ptj.20100150

22. Barrett E, McCreesh K, Lewis J. Reliability and validity of non-radiographic methods of thoracic kyphosis measurement: a systematic review. Man Ther. 
2014;19(1):10-17. doi:10.1016/j.math.2013.09.003

23. Seidi F, Rajabi R, Ebrahimi I, Alizadeh MH, Minoonejad $\mathrm{H}$. The efficiency of corrective exercise interventions on thoracic hyper-kyphosis angle. J Back Musculoskelet Rehabil. 2014;27(1):7-16. doi:10.3233/bmr-130411

24. Coelho DM, Bonagamba GH, Oliveira AS. Scoliometer measurements of patients with idiopathic scoliosis. Braz J Phys Ther. 2013;17(2):179-184. doi:10.1590/s141335552012005000081

25. Brouwer S, Kuijer W, Dijkstra PU, Göeken LN, Groothoff JW, Geertzen JH. Reliability and stability of the Roland Morris Disability Questionnaire: intra class correlation and limits of agreement. Disabil Rehabil. 2004;26(3):162-165. doi:10.1080/09638280310001639713

26. Costa LO, Maher CG, Latimer J, et al. Motor control exercise for chronic low back pain: a randomized placebocontrolled trial. Phys Ther. 2009;89(12):1275-1286. doi:10.2522/ptj.20090218

27. Gutknecht $M$, Mannig A, Waldvogel A, Wand BM, Luomajoki $\mathrm{H}$. The effect of motor control and tactile acuity training on patients with non-specific low back pain and movement control impairment. J Bodyw Mov Ther. 2015;19(4):722-731. doi:10.1016/j.jbmt.2014.12.003

28. Blanchette M-A, Bussières A, Stochkendahl MJ, Boruff J, Harrison P. Effectiveness and economic evaluation of chiropractic care for the treatment of low back pain: a systematic review protocol. Syst Rev. 2015;4(1):30. doi:10.1186/s13643-015-0015-5

29. Ershad N, Kahrizi S. Balance and posture in low back pain patients. J Res Rehabil Sci. 2007;3(1):85-91. [Persian].

30. O'Sullivan P. Diagnosis and classification of chronic low back pain disorders: maladaptive movement and motor control impairments as underlying mechanism. Man Ther. 2005;10(4):242-255. doi:10.1016/j.math.2005.07.001

31. Cook C, Brismée JM, Sizer PS, Jr. Subjective and objective descriptors of clinical lumbar spine instability: a Delphi study. Man Ther. 2006;11(1):11-21. doi:10.1016/j. math.2005.01.002

32. Hall L, Tsao H, MacDonald D, Coppieters M, Hodges PW.
Immediate effects of co-contraction training on motor control of the trunk muscles in people with recurrent low back pain. J Electromyogr Kinesiol. 2009;19(5):763-773. doi:10.1016/j.jelekin.2007.09.008

33. Silva EM, Andrade SC, Vilar MJ. Evaluation of the effects of Global Postural Reeducation in patients with ankylosing spondylitis. Rheumatol Int. 2012;32(7):2155-2163. doi:10.1007/s00296-011-1938-3

34. da Silva DA, de Carvalho ME, de Andrade Mesquita LS. Effects of a protocol with manual therapy and postural techniques for non-specific low back pain. Man Ther Posturology Rehabil J. 2019;17:671. doi:10.17784/ mtprehabjournal.2019.17.671

35. Sheikhi B. Effect of global postural reeducation exercise on pain and hip muscle flexibility in patients with chronic low back pain and movement control dysfunction. Int J Basic Sci Med. 2019;4(4):148-154. doi:10.34172/ijbsm.2019.05

36. Standaert CJ, Weinstein SM, Rumpeltes J. Evidenceinformed management of chronic low back pain with lumbar stabilization exercises. Spine J. 2008;8(1):114-120. doi:10.1016/j.spinee.2007.10.015

37. Hides JA, Jull GA, Richardson CA. Long-term effects of specific stabilizing exercises for first-episode low back pain. Spine (Phila Pa 1976). 2001;26(11):E243-248. doi:10.1097/00007632-200106010-00004

38. Mujika I, Padilla S. Detraining: loss of training-induced physiological and performance adaptations. Part I: short term insufficient training stimulus. Sports Med. 2000;30(2):79-87. doi:10.2165/00007256-20003002000002

39. Hong SM, Hong AR, Shin YA. Effects of detraining on motor unit potential area, muscle function and physical performance based on CNTF gene polymorphism. J Exerc Nutrition Biochem. 2014;18(2):151-160. doi:10.5717/ jenb.2014.18.2.151

40. Lederman E. Neuromuscular Rehabilitation in Manual and Physical Therapy. Edinburgh: Churchill Livingstone; 2010:128. 